\title{
Editorial
}

\section{Etnografia frente aos desafios actuais das ciências sociais}

\section{Consuelo Biskupovic ${ }^{1}$ e Guillermo Brinck Pinsent ${ }^{2}$}

No marco de um encontro pluridisciplinar sobre etnografia realizado no ano 2017 na Universidade Academia de Humanismo Cristiano ${ }^{3}$, emergiu uma pergunta que resulta fundamental resgatar para abrir este dossiê. Por simples que pareça, o questionamento tratava sobre o que nos reúne hoje, o que nos faz conviver, compartilhar recursos e viver em comum. Fazemo-nos a pregunta sobre com que respostas é possível contribuir desde as ciências sociais e como produzir essas respostas. Ora bem, a ferramenta primordial para estudar o "con-viver" é sem dúvida a etnografia, pela permanência e a observação in situ da ou do pesquisador. Praticar a etnografia supõe colaboração; considerada menos como imitação e mais como uma técnica do acoplar-se,

Doutora em Antropologia pela École des Hautes Études em Sciences Sociales de Paris, pesquisadora e professora da Universidade Academia de Humanismo Cristiano. Contato: cbiskupovic@gmail.com

2 Candidato a doutor em Antropologia pela École des Hautes Études em Sciences Sociales de Paris, pesquisador e professor da Universidade Academia de Humanismo Cristiano. Contato: gpbrinck@gmail.com

3 A origem deste número está nas Primeiras Jornadas de Etnografia que foram realizadas em novembro do 2017 na Universidade Academia de Humanismo Cristiano (Santiago, Chile), no marco da comemoração dos 25 anos de existência da Escola de Antropologia da mesma instituição e no início do ano acadêmico dos programas de pós-graduação (Mestrado em antropologia e Mestrado em metodologias de pesquisa e intervenção social). 
assume a impossibilidade de (con)fundir-se com o outro assim como a intervenção da ou do pesquisador nas comunidades observadas: não somos neutros, participamos desse compartilhar, não podemos ser narradores oniscientes da vida em sociedade pois fazemos parte dela. Para podermos responder essas perguntas básicas do con-viver, a etnografia é um processo que nos permite observar condutas e que nos ajuda a assegurar a fiabilidade de nossos dados obtendo-os de "primeira mão".

A partir destes consensos é possível constatar que, além dos diferentes modelos na etnografia, esta é uma forma consciente de estar e desenvolver uma experiência. Esse estar não se esgota em uma leitura literal do que Malinowski propunha quando escreveu que "quanto mais perto se vive de um povoado e mais se vê realmente aos nativos, melhor" (Álvarez, 1994: 94). A etnografia virtual, por exemplo, convida a discutir a ideia clássica sobre a proximidade e sobre o ver "realmente" ou diretamente, permitindo não estar aí em carne e osso, mas mantendo uma presença digital através da escrita, a imagem, as percepções e as representações. A etnografia não é apenas uma experiência pessoal, é um modo de trabalhar que não tem a ver unicamente com pessoas e que já não pode se limitar a "viver o mais perto possível de um povoado". A etnografia visa descrever a vida tal como é vivida e experimentada pelas pessoas em algum lugar e em algum momento, diz-nos Ingold (2017), e isto não implica conformar-nos somente com "acompanhar", presenciar, observar... senão também desafia a criar novas co-presenças e estratégias para estudar as diferentes formas de viver e estar no mundo.

Tal como vemos neste número temático, os âmbitos ou contextos a partir dos quais é possível pensar a etnografia (Estado, mobilização política, migrações ou relações interétnicas) não são excludentes, pois se misturam e é difícil pensar a etnografia sem considerar ao mesmo tempo tanto os marcos identitários, como o papel do Estado e o poder, entre outros. 
Embora os antropólogos com frequência recorram a Malinowski, as perguntas mudam quando já não são os "nativos" ou o "outro" os que estão no centro do interesse. Estamos enfrentados a máquinas virtuais, "bot", blogs, instituições, sistemas, territórios ou paisagens tão heterotópicos como a Antártida ${ }^{4}$. Tal como explica Leticia Katzer no seu artigo incluído neste dossiê "os relatos e as formas de relação construídas no seio das etnografias têm sido e continuam sendo do mais dissímeis". No entanto, mesmo quando as novas buscas etnográficas têm explorado mais alternativas que a de "viver o mais perto de um povoado", há certos temas aos que se regressa constantemente a partir da experiência etnográfica nas ciências sociais. O que há por trás da ideia de instituições tradicionais, de cidadania, de métodos sociais, da política ou do Estado são algumas das reflexões que sustêm este número. Instituições, ideias e categorias são estudadas mais que como estruturas macro, estáveis e rígidas; a etnografia permite dar conta da versão encarnada destas. Assim, em alguns casos, o Estado é encarnado por uma ou duas pessoas com as que há que lidar.

O interesse por abrir estas perguntas e por dar conta da densidade por trás das categorias responde tanto à diversidade da etnografia quanto ferramenta e perspectiva, como ao auge que esta tem tido. Embora esta diversidade tenha aberto a possibilidade de mostrar aspectos que não seria possível conhecer através das chamadas técnicas qualitativas de pesquisa social, o paradoxal é que a etnografia tem chegado a ser um conceito tão usado em diversas disciplinas que tem perdido grande parte do seu significado (Ingold, 2014). O antropólogo Tim Ingold, desde uma visão que não tem estado ausente de polêmica, ocupa-se

4 Entre as palestras no marco das Primeiras Jornadas de Etnografia realizadas em novembro de 2017 na UAHC, contamos com a exposição de Juan Francisco Salazar "Especulação fabulativa e etnografia" da University of Western Sydney. Na sua intervenção sobre como fazer uma etnografia na Antártida, Francisco explicou como realizou um filme etnográfico neste território extremo. Para mais informação consultar o seguinte recurso digital: https://vimeo.com/juansalazar 
de definir os limites do que é a etnografia para protegê-la dos abusos do termo. Esta empresa poderia parecer conservadora se pensamos, como dissemos antes, que as etnografias são dissímeis, mas Ingold acerta quando indica que atualmente etnografia parecesse ser sinônimo de qualitativo, que uma entrevista pode ser por exemplo chamada de "etnográfica" em um informe ou pesquisa mesmo quando se trata de informantes previamente selecionados e a informação obtida é analisada com softwares para produzir "resultados", sem referência nenhuma ao contexto e às práticas daqueles entrevistados (Ingold, 2014). Isto atentaria contra os princípios que, por muito categóricos que pareçam, são a base da etnografia: rigorosidade e compromisso no "tempo longo", laços profundos e sensíveis em relação ao contexto no qual vivemos.

A observação participante é o centro da etnografia, a que nos obriga a questionar nossos supostos sobre o mundo (Shah, 2017). Isto não é próprio da antropologia, tal como veremos nos artigos reunidos neste dossiê, mas sim uma forma de produção de conhecimento através do estar e da ação (Shah, 2017). Tal como indica esta autora, isto implica a longa duração, compreender holisticamente as relações de um grupo, quer dizer, estudar todos os aspectos da vida social e incluir adequadamente intimidade e distância com aqueles "estranhos" que incluímos em nossas pesquisas, tanto humanos como não-humanos. Alpa Shah acrescenta que nos implicarmos nestes passos é um ato político que pode nos permitir desafiar as concepções hegemônicas do mundo e do poder. Por isso, não pode ser algo próprio apenas da antropologia, senão que convoca a todas as ciências sociais e vai além delas.

Tal como indicávamos, o contexto geral das condições de produção de conhecimentos tem imposto suas exigências: o padrão metodológico da sociologia, por exemplo, implicou a adequação da observação participante às exigências positivistas (Ingold, 2014). Isto tem gerado uma mudança importante na maneira de desempenhar-se no trabalho de campo, o que, em um marco cada 
vez mais orientado à produção de artigos mais que monografias, implica uma transformação da etnografia como género literário, quando não o desaparecimento desta sob uma simples menção ao método utilizado.

Contrariamente a uma "norma" etnográfica, tal como existiu entre 1900 e 1960 segundo afirma James Clifford (1983), as transformações progressivas a respeito da etnografia nas diferentes disciplinas no têm sido sistemáticas nem homogêneas em todas as partes. Existem diferenças regionais, de orientação teórica e disciplinar a respeito do que se entende por etnografia e quais são os critérios que fazem com que um trabalho etnográfico seja aceitável. As ciências sociais falam uma multiplicidade de línguas e, quando se nomeia a etnografia, não se faz alusão a um objeto unívoco. No entanto, é difícil ceder à ideia da etnografia como sinônimo de uma experiência fundada em terreno e no "tempo longo", para retomar a expressão que já usou Braudel a respeito da história (Noiriel, 2002). Aliás, julgamos que não deveríamos renunciar a este tempo longo, aos anos em terreno (referimo-nos a um espaço geográfico, virtual ou outro). Tal como afirmou Braudel (1958), tanto em relação ao passado como ao presente, uma metodologia comum e transversal nas ciências que estudam o homem deveria considerar a pluralidade do "tempo social", quer dizer, o instante, o tempo lento, a duração... a história da muito longa duração, a que vai além das dezenas, centenas de anos. Esse tempo que vai além dos eventos, os que muitas vezes são enganosos e não nos permitem compreender a vida social para além de "fatos marcantes". O foco neste tempo longo "é indispensável para uma metodologia comum nas ciências do homem" (Braudel, 1958: 726).

\section{A celebridade da etnografia entre as ciências sociais}

É um fato, a etnografia se tem consagrado como um dos modos de criar conhecimento relevante nas ciências sociais. Nas últimas duas décadas, os estudos etnográficos se têm multiplicado 
tanto quanto sua aceitação (Culyba, Heimer, \& Petty, 2004). Mesmo na era do Big Data, quando os dados se processam algoritmicamente em proporções nunca antes vistas, se tem manifestado a necessidade de complementá-los com a etnografia para enraizar e contextualizar os dados brutos, obtendo o que se tem chamado de Thick Data (Alles \& Vasarhelyi, 2014; Wang, 2013). Até se tem dito -não sem razão- que todos podem fazer etnografia (Sharma, 2016), e assim, junto às clássicas monografias dedicadas aos povos indígenas situados em algum canto mais ou menos afastado do globo, temos etnografias do consumo, dos meios de comunicação, do Estado, da alcova, de Internet, das redes sociais, do exército, das prisões, dos hospitais psiquiátricos, das favelas, das quadrilhas ou da venda de droga nos centros urbanos. Embora a etnografia esteja estreitamente ligada à antropologia, hoje a observação participante é uma prática que transcende as disciplinas.

Apesar dos problemas que tem envolvido a falta de um acordo quanto à definição da etnografia (Ingold, 2017), ao carecer de um sentido unívoco tem podido adaptar-se a diferentes disciplinas facilitando a colaboração entre elas. É possível combinar definições, experimentar, trasladar conceitos, assumindo que sob um mesmo termo podem se esconder uma pluralidade de sentidos y práticas diversas. A etnografia está longe de ser uma equação matemática ou um resultado estatístico (o que não impede que possam ser realizadas pesquisas combinando etnografia, matemática e estatísticas).

Atualmente existe una diversidade de modos de praticar a etnografia. A sociologia dominante, marcada por uma metodologia herdeira do positivismo, recebe de melhor maneira etnografias naturalistas antes que experimentais (etnografia interpretativa, reflexiva, colaborativa, performativa, autoetnografia, etc.). Estas abundam na antropologia e os praticantes da perspectiva qualitativa de pesquisa social como os interacionistas simbólicos, assim como entre aqueles que se contam entre as filas dos estudos pós-coloniais e o feminismo (Culyba et al., 2004). Não são poucos os trabalhos sociológicos baseados em uma etnogra- 
fia intensiva com altos padrões metodológicos e uma profunda reflexão epistemológica em diversos contextos urbanos, reflexão que podemos encontrar em um artigo transcrito de uma palestra de Erving Goffman em 1974 (Goffman, 1989), onde foi convocado a falar sobre como realizava seu trabalho. É interessante aprofundar nesta pergunta de como trabalhamos, pois é aí mesmo onde está o âmbito principal da etnografia. Trabalhos como os de Loïc Wacquant (2006) sobre o boxe, de Phillipe Bourgoise (2010) sobre a venda de drogas em Nova York ou de Javier Auyero e Débora Swistun (2008) sobre o sofrimento ambiental na cidade de Buenos Aires são bons exemplos de etnografias intensivas realizadas em contextos "não-exóticos".

A pesar disto, e da proliferação de revistas e manuais sobre métodos e técnicas qualitativas na pesquisa social onde se publicam cada vez mais trabalhos etnográficos, a tendência geral na sociologia mundial tem sido a de incorporar tangencialmente a etnografia mais como uma moda ou como um modo de complementar os dados quantitativos, incluindo alguns dias de trabalho de terreno ou referindo-se ao trabalho etnográfico de outros para contextualizar suas próprias generalizações (Culyba et al., 2004). Nesta utilização auxiliar da etnografia, a observação participante é vista como uma técnica que entrega dados que, apesar de serem de um tipo diferente aos quantitativos, têm o mesmo status epistemológico. Neste mesmo sentido, o uso aplicado da etnografia em comunicação social, design, consumo e políticas públicas, tende a enfatizar os aspectos técnicos da observação participante orientada a produzir informação específica para algum objetivo prático. Nelas, a etnografia não é um modo específico de conhecimento, mas uma técnica mais dentro de um desenho metodológico.

No entanto, desde suas origens, a prática etnográfica não tem deixado de apresentar desafios epistemológicos, metodológicos, teóricos, éticos e políticos, os quais não têm podido ser eliminados através do recurso da retórica do desenho metodológico. 
Em toda a variedade de perspectivas que contem um mesmo termo, as dificuldades de entendimento e o risco de descrédito são grandes. Por esta razão, é necessário um diálogo interdisciplinar que permita circunscrever os limites do etnográfico que sustêm a colaboração nas ciências sociais e para além delas. Este dossiê visa ser um contributo a dito diálogo através de uma mostra de diversos modos de fazer e conceber a etnografia.

\section{O trabalho artesanal baseado na experiência}

Historicamente, a etnografia tem sido quase um sinônimo de antropologia. Efetivamente, a tradição da tribo antropológica faz do trabalho de campo etnográfico o rito de passo necessário para se transformar em um profissional completo, e à viagem que Bronislaw Malinowski coroou com a publicação dos Argonautas do Pacífico Ocidental em 1922 seu mito de origem (Stocking, 1985). No entanto, apesar de ser verdadeira a ideia de que é impossível pensar a antropologia sem o trabalho de campo etnográfico, a observação participante tem existido sem a antropologia, pois tem tido origens diversas. Em primeiro lugar, toda a etnografia alemã realizada no marco da escola etnológica difusionista no final do século XIX e inícios do XX é legitimamente reclamada pela geografia humana tanto quanto pela antropologia sociocultural (Canal, 2018). Por outro lado, a observação participante foi desenvolvida de maneira autônoma na Escola de Chicago de interacionismo simbólico ou os estudos culturais como os de Paul Willis para responder aos problemas que se levantavam (Restrepo, 2018). Apesar daquilo, grande parte do trabalho etnográfico atual é realizado por profissionais da antropologia nas condições que lhe têm dado suas características: observação participante com permanência a tempo completo e por um período prolongado das práticas sociais e o sentido que essas práticas têm para os próprios atores (Guber, 2004, 2017; Restrepo, 2018). Estas condições, estabelecidas no final do século XIX e encarnadas na figura de Malinowski, são as que se continuam aplicando para qualquer 
trabalho etnográfico, independentemente das circunstâncias em que sejam realizadas: uma comunidade indígena, as redes sociais digitais ou no estudo de uma política pública. Evidentemente, a etnografia tem experimentado transformações importantes, tal como o mundo no qual ela se põe em jogo. Assim, de umas etnografias localizadas em espaços remotos e isolados, como se os povos observados estivessem fora do tempo e da influência externa em um eterno presente etnográfico (Fabian, 2002), foi desenvolvida a perspectiva situacional para compreender desde um ponto de vista microscópico as estruturas que faziam inteligíveis as relações interétnicas nas cidades de África do Sul durante o período colonial (Balandier, 1970; Gluckman, 2003; Mitchell, 1959; Van Velsen, 1978); e começaram a serem realizadas etnografias históricas (Sahlins, 1997, 2001) e multisituadas (Hannerz, 2003; Marcus, 1995) que considerassem a maneira em que os atores e os grupos se relacionam com o sistema político, econômico e cultural de escala mundial, passando a ser considerados contemporâneos antes que primitivos ou mesmo cosmopolitas (Agier, 2012; Althabe, 2003; Augé, 1995). Estas mudanças têm exigido o desenvolvimento da interdisciplinaridade e a incorporação de diversas técnicas, tecnologias e formas de análise quantitativos e qualitativos para fazer viável a sondagem em terreno. Porém, a etnografia continua sendo una prática artesanal posto que seu sucesso depende da experiência de encontro entre a pessoa que observa e a pessoa observada no contexto de realização de suas interações cotidianas.

\section{Complexidades de um termo}

A experiência pessoal sobre a qual se baseia a etnografia a diferencia das técnicas qualitativas de pesquisa posto que nela o observador no se limita à recolha de dados como se estivessem aí esperando para serem recolhidos e analisados, senão que está comprometido ontologicamente (Ingold, 2017) em um processo de co-conhecimento com aquelas pessoas que conformam o con- 
texto que quer compreender. Devido a que na etnografia se quer descrever a maneira em que um grupo, uma comunidade, um contexto se estruturam, e o sentido que neste contexto se entrega às ações dos sujeitos que o compõem, a empresa etnográfica depende de uma sensibilidade particular perante "uma maneira de ser em e ver o mundo culturalmente estabelecida" (McGranahan, 2018, p. 2). A etnografia seria ontológica e epistemológica ao mesmo tempo (McGranahan, 2018), o que sem dúvida dificulta sua inclusão nos cânones do desenho metodológico imperante nas ciências sociais (Ingold, 2017).

A palavra etnografia pode se referir ao mesmo tempo a uma perspectiva, um método e um texto (Guber, 2017); ou simultaneamente a uma técnica, um método e um tipo de escrita (Restrepo, 2018); ou também a uma teoria, um método e uma forma de escrita (McGranahan, 2018). Como temos dito, a etnografia normalmente é vista apenas como uma técnica, a observação participante, o qual supõe limitar a experiência social total que poderia ter quem observa as atividades de coleta de informação, voltando a suas interações sempre instrumentais e a seus interlocutores uns meros informantes, negando assim o propósito da etnografia, que é observar as relações em seu contexto natural participando delas. De modo que se a etnografia tem uma dimensão técnica, não pode ficar reduzida a ela sem sacrificar aquilo que a define. A antropóloga Carole McGranahan tem definido a etnografia antropológica como "uma prática de conhecimento corporal, empírica e experiencial, baseada no trabalho de campo e na observação participante" (McGranahan, 2018, p. 4). Muito tempo antes, em 1974, Ervin Goffman definia a observação participante como uma técnica, mas uma técnica "na qual me parece que são obtidos dados sometendo-se a própria pessoa, seu próprio corpo e sua própria personalidade, e sua própria situação social, ao conjunto de contingências que incidem sobre um conjunto de indivíduos, de modo que é possível penetrar física e ecologicamente seu círculo de respostas a sua situação social, ou sua situação laboral, ou situação étnica, o a que for" (Goffman, 1989, p. 125). De maneira 
que, tanto em antropologia como em sociologia (ao menos no interacionismo simbólico), guardando todos os matizes que cabem aqui, a etnografia tem sido entendida e praticada como uma experiência pessoal total. É por isso que, com frequência, as pessoas que realizam etnografia definem-se a si próprias como etnógrafos mais do que como observadores ou pesquisadores (Mannay \& Morgan, 2015).

Evidentemente, não todos os terrenos permitem as mesmas condições, e os objetos das diversas disciplinas têm tensionado estes fatores, chamando de etnografia a práticas que distam da imersão profunda e a estadia permanente no campo para participar ativamente de todas as instâncias possíveis. A etnografia no ciberespaço, por exemplo, não supõe uma experiência corporal; o trabalho em instituições hierarquizadas, como o Exército ou um hospital psiquiátrico, não permite a participação plena e com frequência se limita à realização de entrevistas; o trabalho com réus em um presídio impõe uma barreira a quem, sem ser mais um prisioneiro, deseje realizar um trabalho etnográfico. E, porém, temos etnografias sobre estes contextos. Uma resposta tem sido a de adaptar o método às condições do campo (assim como às do orçamento e os prazos cada vez mais apertados dos mandantes), como com a denominada observação flutuante (Pétonnet, 1982), que emula ao passeante citadino para incorporar os ritmos e fluxos de um espaço urbano sempre em formação. Ou a chamada etnografia focalizada (Knoblauch, 2005), que se apresenta como uma versão complementar da etnografia convencional de curta duração mas de intensa interação comunicativa. A outra resposta é elaborar um dispositivo de controle da observação e a participação na etnografia, apresentando-a antes como uma abordagem holística de alcance epistemológico e existencial ao mesmo tempo.

\section{Etnografia, método e reflexividade}

Neste cenário é lícito perguntar-se quais seriam os limites do etnográfico, do que a distingue da observação participante e que 
garantias de rigorosidade pode apresentar um método ou uma técnica na qual se está à mercê dos tempos e as características do contexto. Em que sentido pode se falar de etnografia quando a tarefa investigativa se restringe quase na sua totalidade a entrevistas em profundidade? Como temos visto, há quem defenda que uma entrevista nunca poderia ser etnográfica (Ingold, 2017). Para outros, como Eduardo Restrepo ou Rosana Guber, uma entrevista pode ser etnográfica na medida em que considere o que nela se diz como uma expressão do que se está fazendo na situação de entrevista, vista como una relação social. Deste modo, a etnografia como método ou enquadramento epistemológico considera uma série de técnicas (observação participante, entrevistas, genealogias, histórias de vida) que adquirem sentido etnográfico situando-as em seu contexto de produção sociocultural (Restrepo, 2018). Rosana Guber, seguindo nisto a Harold Garfinkel, põe o acento na reflexividade dos atores tanto ao momento de produzir as interações próprias do contexto estudado como aquelas próprias do estudo de dito contexto (Guber, 2017). Assim, as informações (as respostas a perguntas diretas em uma entrevista, e as interações e atividades observadas na participação do etnógrafo) não são um reflexo objetivo de um contexto transcendente (estrutura, cultura, identidade, etc.), mas o resultado das múltiplas reflexividades que consideram e reagem à presença, atributos, ações e perguntas do etnógrafo. É tarefa do observador trabalhar essas aparentes distorções como dados etnográficos para assim restituir o sentido social das ações e dos ditos dos atores.

É a isto que se refere Jaime González no artigo que publica neste dossiê sobre os intelectuais indígenas quando, seguindo nisto a Giddens, assume a necessidade de considerar a "dupla hermenêutica" da situação etnográfica: "a pesquisa de campo com estes agentes dependerá também da capacidade de interpretação dos sujeitos de estudo e do efeito que isto gerará na interação com o pesquisador. Desta maneira, as tendências intelectuais que se possam identificar em terreno estarão mediadas pela consciência destes agentes e a leitura intelectual que realizem do etnó- 
grafo que tiverem em frente". De igual maneira, Olivia Leal, no texto que publica aqui, analisa os "processos de interpelação de ida e volta entre os sujeitos étnicos e o etnógrafo sobre os dados recolhidos, as formas de registro e classificação de informação que deram forma em seu conjunto ao texto etnográfico final. De fato, consideram minha própria tese como parte de seu patrimônio material como coletivo étnico ao considerarem que documento "apenas uma parte, do muito que se pode dizer dos chilas»".

A nosso entender este é um componente essencial da etnografia. Não se trata só de observar aquilo em que se participa, mas de manter uma atenção (flutuante ou dirigida) e uma vigilância epistemológica. Neste sentido, a interação na observação participante é semelhante à relação estabelecida na prática psicanalítica onde o material analisado são as lembranças objetivadas do analisando como a transferência e a contratransferência na qual se repetem os conflitos básicos do analisando projetando-os na figura do analista na medida em que este reage também a ela. No trabalho etnográfico, este jogo especular deve ser registrado e considerado mesmo quando for aplicada uma pesquisa, uma entrevista ou una genealogia, considerando a análise da transferência e a da contratransferência, e ainda colocando maior ênfase no segundo, posto que permitirá controlar a produção e a análise dos dados (Devereux, 2008). Isto não envolve necessariamente um regresso obsessivo sobre questões de autoridade etnográfica e crise de representação. Também não supõe outorgar um privilegio ao "autoetnográfico" (embora o dote de um fundamento epistemológico), posto que a etnografia deve sempre descrever uma realidade concreta em termos fidedignos e de maneira rigorosa. A etnografia deve dizer algo sobre seu objeto (que não os sujeitos em si mesmos), sobre a relação entre o mesmo e o outro, o jogo das alteridades e o sentido social que se deriva delas (Augé, 1995, 1996). Para atingir aquilo, deve-se considerar à etnografia como um conhecimento situado no qual as reflexividades de uns e outros põem em jogo na mesma pesquisa uma relação da mesma natureza que aquela 
que se busca descrever. Esta é tal vez a principal dificuldade da "metodologização" da etnografia, se nos for permitido o barbarismo, o fato de que só seja um método a posteriori, quando as observações realizadas no contexto de interação e registradas no caderno de campo passam a fazer parte de uma descrição escrita ou visual que pretende compreender ou explicar um fenômeno geral em um contexto particular (Ingold, 2017).

\section{O conhecimento etnográfico, experiência encarnada e politicas acadêmicas}

O caráter situado do conhecimento etnográfico tem aberto a possibilidade de falar de teoria etnográfica (da Col \& Graeber, 2011; McGranahan, 2018). Para além das polêmicas a respeito da perspectiva teórica que implica esta expressão (Ingold, 2017), a questão do alcance generalizador do conhecimento sobre contextos restringidos como os que os etnógrafos costumam abordar (aldeia, sala de aula, instituição, bairro, etc.) tem sido definida por Clifford Geertz apelando ao caráter microscópico do conhecimento etnográfico na medida em que não estuda pequenas localidades senão temas de grande e profundo alcance nestes lugares através do que denomina descrição densa, que corresponde a explicar os fatos apelando ao sentido social da ação (Geertz, 1992). Assim, seria possível falar de conhecimento etnográfico na medida em que este dá conta de conceitos encarnados em uma experiência concreta socioculturalmente informada. Este modo de construir conhecimento, enfrentando noções, conceitos e modelos locais com modelos, conceitos e noções teóricas elaboradas na academia é a que permite renovar e aumentar permanentemente o repertório conceitual das ciências sociais. Na medida em que o conhecimento etnográfico supõe uma exposição a uma configuração da realidade e da experiência diferentes, possibilita além de uma crise teórica e epistemológica, uma crise ontológica no etnógrafo que tenta expressar em sua descrição etnográfica. 
Em seu artigo publicado neste dossiê, Leticia Katzer, assegura que "a especificidade da etnografia é a de ser uma concepção e prática de conhecimento que procura compreender os fenômenos sociais desde a perspectiva de seus membros (Guber 1991[2004], 2001) esta só é possível quando se estabelece autenticamente uma relação entre o etnógrafo/a e esses outros." A autora acrescenta que foram as "relações etnográficas" em terreno as que guiaram suas atividades acadêmicas, decisões e perguntas de pesquisa. Este processo é fundamental e necessário ainda quando os critérios de avaliação hoje (relativos a fundos, projetos ou medir produtividade ou publicações) constringem as pesquisadoras e os pesquisadores a circunscrever a pesquisa a um lapso de tempo breve, a quantificar entrevistas e medir resultados. $\mathrm{O}$ desafio de materializar etnografias de tempo longo em um contexto acadêmico marcado pela maximização do tempo e dos resultados na pesquisa é sobretudo hoje um desafio.

Neste contexto, mais do que a outras disciplinas das ciências sociais, à antropologia é questionada pelo rigor e sistematicidade "científica", a capacidade de produzir "conhecimentos confiáveis" através da etnografia, instando-a a predefinir de antemão "mostras representativas". Apesar de que nas pesquisas a população estudada não é homogênea e por tanto é central dar conta da diversidade, não sempre esta pode ser explicada através de uma amostragem representativa. Muitas vezes a etnografia centra-se em grupos que têm certas ideias parecidas, o que pertencem a grupos e/ou classes similares, por exemplo, ao estudar um partido político, uma ONG, ou a tatuagem em um grupo de jovens. A riqueza não sempre está na "representatividade" para responder a pergunta de pesquisa, mas também na particularidade, no que faz único a esse grupo, em suas características, em como seus membros se auto-percebem, em como existem quanto grupo. A etnografia permite rastrear as motivações e significados dos que os envolvidos dão conta, como vivem e interpretam eles próprios sua vida, sua pertença aos grupos ou categorias sociais, sua própria existência. 
A etnografia, quanto experiência de campo, vai modificando nossas perguntas assim como as perguntas que fazemos aos "nativos" e o que observamos. Neste marco, as maneiras em que as pessoas com as que interagimos em terreno pensam, dão conta de seu entorno, explicam e refletem com os etnógrafos, deveriam ser vistas, tal como sugere Julieta Quirós, "menos como um ponto de vista «intelectual» (i.e.: formas de conceber e significar mundos) e mais como um ponto de vista «vivencial» (formas de fazer e criar vida social)" (Quirós, 2015: 47).

Muitos dos aspectos que estão no centro das monografias, não pareciam relevantes ou nem sequer são considerados na fase inicial de desenho da pesquisa. E é comum que emerjam novos problemas e novas perguntas durante o terreno. Neste sentido, uma característica distintiva da etnografia é antes que circunscrever temas, abrir novas interrogantes. Como temos dito, nesta dinâmica de ir e vir do terreno, a reflexividade resultante da experiência compartilhada, da "exposição" e da vivência são partes centrais da etnografia. Ora bem, estas sensibilidades e compromissos não encaixam com os marcos e padrões cada vez mais exigidos nos protocolos para obter fundos de investigação, bolsas, avaliações e rendições de nossos trabalhos. Ainda mais quando "a pergunta de pesquisa nunca é uma formulação sabida. O objeto e perguntas de pesquisa são, precisamente, parte do que vamos buscar ao campo" (op. cit.: 54). Isto é um verdadeiro desafio tanto para o corpo estudantil que realiza etnografias e devem justificá-las, como para os e as pesquisadoras/es que devem "adaptar" a etnografia aos padrões, requisitos e formulários do campo acadêmico atual. Por outro lado, a pesquisa etnográfica deve se adaptar ao formato do artigo científico, o qual deve dar espaço a todos os componentes de um trabalho científico e ao mesmo tempo a uns dados etnográficos, de contexto e situação, que requerem de um espaço muito maior do que o das tabelas de dados quantitativos ou as citas de entrevistas da pesquisa qualitativa, para referirem sempre a una problemática de alcance geral que lhes dê relevância e os insira no campo de reflexão disciplinar 
ou temático. Por mais que surjam novos mundos por explorar (citas digitais, mundos carcerários, científicos localizados em una base na Antártida, etc.), é possível determinar que a etnografia é um método, uma técnica e um modo de escrita sólido e dúctil que pode enfrentar estes novos desafios. Apresentamos aqui uma mostra como prova daquilo.

\section{Organização do dossiê}

O dossiê que se apresenta neste número compõe-se de oito artigos que se agrupam em quatro grandes temas, primeiro temos dois artigos que nos permitem contextualizar a etnografia como conceito, historicamente e teoricamente. $\mathrm{O}$ artigo "Etnografia e empirismo" de Cristopher Valdés San Martín aborda a etnografia desde una reflexão epistemológica e seguindo uma consideração fenomenológica da história da mesma, principalmente desde a perspectiva de Husserl. Propõe que o conhecimento antropológico distingue-se por seu afã totalizador na busca por compor o "mundo" do outro a partir de um conhecimento não conceitual e apegado à experiência que contudo permita a emergência de um sujeito filosofante. Logo, o artigo "Etnografias desérticas. Reflexões desde uma antropologia do nomadismo" de Leticia Katzer combina uma reflexão crítica sobre a etnografia com sua própria experiência de campo com população indígena Huarpe na província de Mendoza, Argentina. Dialoga com a filosofia continental de Derrida, Cacciara, Deleuze e Guattari propondo-a como uma expressão de ciência nômade na medida em que põe o olho na pegada, o rastro e o espectro antes que em regularidades que levam a modelos fechados. Desta maneira, Katzer faz dialogar seu processo e sua experiência etnográfica com a filosofia pósestruturalista para dar fundamento a sua proposta de etnografia colaborativa.

Logo, desde uma etnografia política, o trabalho de Pia Rius permite ver "o que há por trás" do aparente. Desta maneira, Rius investiga "a experiência do político" para ver como uma popula- 
ção autogere cotidianamente "a organização coletiva, o trabalho, a alimentação ou as produções e consumos culturais". O tempo longo de sua etnografia lhe permite apreender uma temporalidade que vai desvendando como se define o "trabalho 'sem patrão'"

Desde o problema global que enfrentam os migrantes na atualidade, o trabalho de Alberto Farías "Olhares etnográficos e representações de cidadania em jovens indígenas, migrantes purépechas do México" reflete também desde uma etnografia política sobre a migração indígena purépecha para os Estados Unidos. Apresenta os resultados de uma pesquisa qualitativa, colaborativa e de tipo etnográfico da situação de discriminação e racismo vivida por jovens purépechas após terem migrado e regressado a suas comunidades de origem no México. Este trabalho dá conta de um problema relevante, a saber, as práticas de discriminação e racismo contemporâneas considerando as comunidades indígenas em suas possibilidades de devirem no contexto atual.

Neste dossiê apresentamos duas etnografias urbanas. Na primeira delas ("Etnografia institucional como aproximação ao habitar cotidiano") seus autores, Jirón, Orellana e Imilán, após uma pormenorizada descrição do que é a Etnografia Institucional (EI), explicam como esta abordagem é susceptível de ser aplicada aos estudos do habitar urbano. Em particular, os autores centram-se no caso do Programa de Recuperação de Bairros Quiero Mi Barrio (MINVU) e como os conhecimentos e saberes que mediam entre os que habitam em um bairro de Santiago e a mesma intervenção, assim como o regime institucional que rodeia dita intervenção. Segundo eles, o EI vai além de estudar unicamente as experiências cotidianas, propondo-se indagar "nas relações sociais, a organização e as relações de controle" que "emergem dos complexos institucionais que coordenam e administram ditas experiências".

O segundo trabalho é o de Olivia Leal Sorcia, "Desafios do trabalho etnográfico com indígenas urbanos em cidades mexica- 
nas". Neste texto, Leal elabora uma reflexão crítica sobre o método etnográfico e suas técnicas (observação participante, caderno de campo e entrevistas em profundidade) a partir de seu trabalho de campo realizado com indígenas residentes na Cidade do México (chilangos), considerando os desafios que supõe a agência das e dos atores na maneira em que a etnógrafa registra, analisa e escreve, e o papel que cumprem seus escritos no fenômeno que busca compreender.

Finalmente, fechamos o dossiê com duas etnografias que abordam a problemática étnica desde diferentes casos. O primeiro trabalho, "Intelectualidade étnica. Proposta teórico-metodológica de um objeto de indagação" de Jaime González, desenvolve um modelo para compreender a intelectualidade étnica sobre a base da própria experiência etnográfica entre os Purhépecha do México e os Aymara do Chile. Mostra a versatilidade do método etnográfico com sujeitos para os quais o método não foi desenhado. $\mathrm{O}$ texto considera as dificuldades desta pesquisa não tradicional, indicando a necessidade de incorporar a análise da dupla hermenêutica que se produz na situação etnográfica, onde como o pesquisador, os intelectuais têm graus acadêmicos e um nível de agência do conhecimento do que trata o processo etnográfico.

O texto de Roberto Narváez Collaguazo intitulado "A etnografia: instrumento de pesquisa em antropologia jurídica. $\mathrm{O}$ caso de um povo amazônico" aprofunda nos fundamentos socioculturais da guerra no caso dos waorani da Amazônia equatoriana desde a perspectiva da antropologia jurídica, mostrando até que ponto a etnografia é relevante para esta subdisciplina. Com constantes referências ao caderno de campo, mostra o modo em que as vinganças, as estratégias e as alianças fazem parte de uma maneira de viver em comum por meios como assaltos, escaramuças e enfrentamentos, todos os quais são julgados pelo Estado como faltas à lei e à ordem cívica mas que desde um olhar etnográfico podem ser entendidos como parte de um modo tradicional de participar na vida social e ser reconhecido pelos outros. 
Este dossiê apresenta uma interessante variedade de temáticas, fenômenos e problemas, teóricos, metodológicos e epistemológicos em torno da etnografia. Confiamos em que esta seleção não é apenas uma mostra da maneira em que os e as etnógrafas estão praticando a etnografia e os problemas que se estão levantando a respeito desta prática, senão que contribuirá a possibilitar o diálogo entre pessoas que provêm de países, disciplinas e tradições sociais, culturais, ideológicas e intelectuais dissímeis.

\section{Bibliografia}

Agier, M. (2012). Pensar el sujeto, descentrar la antropología. Cuadernos de antropología social, (35), 9-27.

Alles, M., \& Vasarhelyi, M. A. (2014). Thick data: adding context to big data to enhance auditability. International Journal of Auditing Technology, 2(2), 95-108. https://doi.org/10.1504/IJAUDIT.2014.066237

Althabe, G. (2003). Antropología del mundo contemporáneo y trabajo de campo. Alteridades, 13(25), 7-12.

Álvarez Roldan, A. (1994). La invención del método etnográfico: reflexiones sobre el trabajo de campo de Malinowski en Melanesia. Antropología. Asociación madrileña de antropología, 1994, 83-100.

Atkinson, P. (2015). For ethnography. Los Angeles: SAGE.

Augé, M. (1995). Hacia una antropología de los mundos contemporáneos (1a. ed). Barcelona, España: Gedisa.

Augé, M. (1996). El sentido de los otros: actualidad de la antropología (1a.ed). Barcelona, España: Paidós.

Auyero, J., \& Swistun, D. A. (2008). Inflamable: estudio del sufrimiento ambiental (1a ed). Buenos Aires: Paidós.

Balandier, G. (1970). El concepto de «situación» colonial. Guatemala: Ministerio de Educación.

Bourgois, P. I. (2010). En busca de respeto: la venta de crack en Harlem. San Juan, P.R.: Ediciones Huracán.

Braudel, F. (1958). Histoire et Sciences sociales : La longue durée. Annales, 13(4), 725-753. https://doi.org/10.3406/ahess.1958.2781 
Canal, R. de la. (2018). La Geografía y la Antropología: vinculaciones en sus recorridos históricos. Huellas, 22(2), 99-105. https:/ / doi. org/DOI: http:/ /dx.doi.org/10.19137/huellas-2018-2215

Culyba, R. J., Heimer, C. A., \& Petty, J. C. (2004). The Ethnographic Turn: Fact, Fashion, or Fiction? Qualitative Sociology, 27(4), 365-389. https://doi.org/10.1023/B:QUAS.0000049238.27735.79

da Col, G., \& Graeber, D. (2011). Foreword: The return of ethnographic theory. HAU: Journal of Ethnographic Theory, 1(1), vi-xxxv. https://doi.org/10.14318/hau1.1.001

Devereux, G. (2008). De la ansiedad al método en las ciencias del comportamiento. México, D.F.: Siglo Veintiuno.

Fabian, J. (2002). Time and the other: how anthropology makes its object. New York: Columbia University Press.

Geertz, C. (1992). Descripción densa: hacia una teoría interpretativa de la cultura. En La interpretación de las culturas (pp. 19-41). Barcelona: Gedisa Editorial.

Gluckman, M. (2003). Análisis de una situación social en zululandia moderna max gluckman la organización social. Bricolage, (1), 34-49.

Goffman, E. (1989). On fieldwork. Journal of Contemporary Ethnography, 18(2), 123-132. https://doi. org $/ 10.1177 / 089124189018002001$

Guber, R. (2004). El salvaje metropolitano: reconstrucción del conocimiento social en el trabajo de campo (1a. ed. en Editorial Paidós). Buenos Aires: Paidós.

Guber, R. (2017). La etnografía: método, campo y reflexividad. Ciudad de México: Siglo XXI Editores.

Hannerz, U. (2003). Being there... and there... and there!: Reflections on Multi-Site Ethnography. Ethnography, 4(2), 201-216. https://doi.org/10.1177/14661381030042003

Ingold, T. (2014). That's enough about ethnography! HAU: Journal of Ethnographic Theory, 4(1), 383-395. https://doi.org/10.14318/ hau4.1.021

Ingold, T. (2017). ¡Suficiente con la etnografía! Revista Colombiana de Antropología, 53(2), 143-159.

Knoblauch, H. (2005). Focused Ethnography. Forum Qualitative Sozialforschung / Forum: Qualitative Social Research, 6(3). https:/ / doi.org/10.17169/fqs-6.3.20 
Mannay, D., \& Morgan, M. (2015). Doing ethnography or applying a qualitative technique? Reflections from the "waiting field'. Qualitative Research, 15(2), 166-182. https://doi. org $/ 10.1177 / 1468794113517391$

Marcus, G. E. (1995). Ethnography in/of the World System: The Emergence of Multi-Sited Ethnography. Annual Review of Anthropology, 24(1), 95-117. https://doi.org/10.1146/annurev. an.24.100195.000523

McGranahan, C. (2018). Ethnography beyond method: the importance of an ethnographic sensibility. Sites: A Journal of Social Anthropology \& Cultural Studies, 15(1).

Mitchell, J. C. (1959). The Kalela dance: aspects of social relationships among urban Africans in Northern Rhodesia. Manchester: Manchester University Press.

Noiriel, G. (2002). Comment on récrit l'histoire. Les usages du temps dans les Écrits sur l'histoire de Fernand Braudel. Revue d'histoire du XIXe siècle. Société d'histoire de la révolution de 1848 et des révolutions du XIXe siècle, (25), 57-81. https:/ / doi. org $/ 10.4000 /$ rh19.419

Pétonnet, C. (1982). L'Observation flottante. L'exemple d'un cimetière parisien. L'Homme, 22(4), 37-47. https://doi.org/10.3406/ hom.1982.368323

Quirós, J. (2015). Etnografiar mundos vívidos. Desafíos de trabajo de campo, escritura y enseñanza en antropología. Publicar-En Antropología y Ciencias Sociales, 0(17). Recuperado de http://ppct.caicyt.gov.ar/index.php/publicar/article/ view $/ 4914$

Restrepo, E. (2018). Etnografía : alcances, técnicas y éticas (1. ${ }^{a}$ ed.). Lima: Fondo Editorial de la Universidad Nacional Mayor de San Marcos. Recuperado de http://bdjc.iia.unam.mx/items/ show $/ 77$

Sahlins, M. (1997). Islas de historia: la muerte del capitán Cook metáfora, antropología e historia (3a.ed). Barcelona: Gedisa.

Sahlins, M. (2001). Dos o tres cosas que sé acerca del concepto de cultura. Revista Colombiana de Antropología, (37), 11.

Sharma, D. (2016, febrero 11). Everybody's an Ethnographer! Recuperado 19 de noviembre de 2018, de https:/ / ethnographymatters.net/blog/2016/02/11/everybodys-an-ethnographer/ 
Stocking, G. W. (1985). The Ethnographer's Magic. Fieldwork in British Anthropology from Tylor to Malinowski. En G. W. Stocking (Ed.), Observers observed: essays on ethnographic fieldwork (Nachdr., pp. 70-120). Madison, Wis.: Univ. of Wisconsin Pr.

Shah, A. (2017). Ethnography? Participant observation, a potentially revolutionary praxis. HAU: Journal of Ethnographic Theory, $7(1), 45-59$.

Van Velsen, J. (1978). The Extended-case Method and Situational Analysis. En A. L. Epstein (Ed.), The Craft of social anthropology (pp. 129-149). Oxford ; New York: Pergamon Press.

Wacquant, L. J. D. (2006). Entre las cuerdas: cuadernos de un aprendiz de boxeador. Buenos Aires: Siglo XXI.

Wang, T. (2013, mayo 13). Big Data Needs Thick Data. Recuperado 19 de noviembre de 2018, de https: / / ethnographymatters.net/ blog/2013/05/13/big-data-needs-thick-data/ 